\title{
Permanência e movimento na cidade: interseções entre espaço, lugar e afetividade
}

\section{Permanence and movement in the city: intersections between space, place and affectivity}

\section{Permanencia y movimiento en la ciudad: las intersecciones entre espacio, lugar y afectividad}

\section{Camila Klein*}

Universidade Federal de Santa Catarina - UFSC, Florianópolis, Santa Catarina, Brasil

Ariane Kuhnen**

Universidade Federal de Santa Catarina - UFSC, Florianópolis, Santa Catarina, Brasil

Nikolas Olekszechen $* * *$

Universidade de São Paulo - USP, São Paulo, São Paulo, Brasil

\begin{abstract}
RESUMO
O presente trabalho propõe o diálogo entre dois estudos empíricos, e problematiza os conceitos de lugar e de afetividade, a fim de compreender as relações pessoa-cidade, no âmbito da Psicologia Ambiental. O primeiro estudo investigou o modo como ciclistas são afetados pelo ambiente urbano e como dele se apropriam durante seus deslocamentos diários e o segundo procurou compreender a relação que os habitantes de uma cidade têm com a praça central. Ambos os estudos ancoraram-se no conceito de afetividade na cidade como categoria de análise, entendendo-a como o motor da açãotransformação das pessoas na relação com o entorno sócio físico. Embora tenham sido realizadas em contextos distintos, as pesquisas utilizaram a entrevista semi-estruturada como técnica de produção dos dados. As falas dos participantes foram transcritas na íntegra e submetidas a análise de conteúdo. Neste trabalho foram selecionados os fragmentos de narrativas que pudessem alicerçar a discussão acerca de afetividade na cidade e a constituição de lugares. Ao estabelecer a interlocução entre ambas as investigações pode-se considerar, à guisa de conclusão, que, se o lugar é estabelecido pelas e nas biografias que se constroem no espaço vivido, não implica necessariamente em pausa ou enraizamento, mas se refere antes aos modos como as pessoas se afetam e conectam-se ao entorno.
\end{abstract}

Palavras-chave: psicologia ambiental, afetividade, lugar, praça, mobilidade.

\section{ABSTRACT}

This paper proposes a dialogue between two empirical studies, and it discusses the place and affection concepts in order to understand the relations person-city, under the Environmental Psychology. The first study 
investigated how cyclists are affected by urban environment and how they appropriate it during daily commutes, and the second study sought to understand the relationship that the inhabitants of a city have with the central square. Both studies are anchored in the concept of affectivity in the city as an analysis category. It understands as the people actiontransformation engine in relation to the surrounding physical partner. Although they have been performed in different contexts, the researches used a semi-structured interview as data production technique. The participants' speeches were fully transcribed and they were subjected to content analysis. This research selected the narrative fragments that could underpin the affectivity discussion in the city and the creation of places. By establishing dialogue between both investigations it can be considered if the place is established by and in the biographies that are built in the living space, it does not imply necessarily paused or rooting, but it is referred the ways how people affect and connect to the surroundings.

Keywords: environmental psychology, affectivity, place, square, mobility.

\section{RESUMEN}

Este trabajo propone un diálogo entre dos estudios empíricos, se analizan los conceptos de sitio y de la afectividad con el fin de comprender la relación persona-ciudad, desde la Psicología Ambiental. El primer estudio investigó cómo los ciclistas se ven afectados por el entorno urbano y la forma en que se apropia durante sus desplazamientos diarios, por otro lado, el segundo estudio trató de comprender la relación que los habitantes de una ciudad tienen con su plaza central. Ambos estudios están apoyados en el concepto de la afectividad en la ciudad como una categoría de análisis, entendiendo ésta como fuerza impulsora de la acción-transformación de las personas en relación con el socio físico que le rodea. Aunque se han llevado a cabo en diferentes contextos, la investigación utilizó la entrevista semi-estructurada como técnica de producción de conocimiento. Los discursos de los participantes fueron transcriptos en su totalidad y se presentados para hacer la análisis del contenido. En este trabajo se seleccionaron los fragmentos narrativos que podrían sostener la discusión de la afectividad en la ciudad y la creación de sitios. Al establecer un diálogo entre ambas investigaciones se puede considerar que, en conclusión, que si el lugar se establece por y en las biografías que se construyen en el espacio de vida, no implica necesariamente pausa o arraigamiento, pero bien se refieren a las formas cómo las personas se conectan y afectan al entorno.

Palabras clave: psicología ambiental, afectividad, lugar, plaza, mobilidad.

\section{Introdução}

A progressiva concentração de pessoas nas cidades aliada ao atual padrão de produção e consumo característico do sistema capitalista impactam de maneira significativa não só os ambientes urbanos, mas a vida das pessoas, o modo como elas ocupam e circulam por esses espaços. Sintomas de uma época, os problemas decorrentes da urbanização devem ser compreendidos como desdobramentos históricos do processo de produção e acumulação de bens, que pressupõem o ambiente como propriedade a ser explorada e não um bem comum. 
No horizonte da construção das cidades europeias, notadamente compreendido entre os séculos XVIII e XIX, essa exploração se evidencia na divisão do uso dos espaços, pela criação de ambientes delimitados para atenderem necessidades específicas. As ruas e os espaços públicos eram entendidos como locais de passagem e de velocidade, enquanto que os cafés e pubs eram locais de permanência e de intercâmbios, indicando a separação entre as esferas pública e privada na cidade (Sennet, 2003).

Os desdobramentos disso podem ser exemplificados pelas reformas urbanas ocorridas em cidades como Londres e Paris a partir do século XVIII. Ao favorecer o livre fluir das pessoas e imprimir velocidade na vida das cidades, o planejamento urbano acabou fomentando um "sentimento de estranheza geral" entre as pessoas (Sennet, 2003), que tem expressão na figura do individualismo. Desse modo, a valorização da velocidade e do movimento desligou os corpos dos lugares por onde passam, diminuindo as possibilidades de trocas e encontros, isolando indivíduos e criando uma "ética da indiferença" nas cidades.

A alienação entre indivíduo e espaço, promovida pela velocidade, homogeneíza a experiência urbana que pode emergir desse encontro. Nesse sentido, o espaço percorrido é antes de tudo um entrave ao exercício da liberdade individual, que deve ser superado imediatamente e com igual rapidez. Para Lefebvre (2001), há um investimento histórico na constituição das cidades que contribuiu para a decadência da vida coletiva. Propositado ou não, o fato é que a moderna configuração do tecido urbano resultou na dissolução da própria urbanidade - que pressupõe a vida na cidade como o lócus de convívio das diferenças.

Esses argumentos auxiliam a compreender que ao longo do processo de urbanização, os modos de ser e estar nas cidades correspondem à sua época e às formas urbanísticas que adotam. No que tange à circulação de pessoas, de um lado têm-se as cidades europeias medievais, que estimulam a caminhada, e em outro extremo, as cidades modernistas marcadas pelo distanciamento e segregação na disposição de serviços no território, que convocam ao uso do automóvel (Schiller, Bruun, \& Kenworthy, 2010).

Diante disso, é necessário lançar o olhar à vida pulsante das cidades e àquilo que escapa ao concreto e a lógica da aceleração. Tomando o panorama urbano como contexto de análise e amparados pela psicologia ambiental, este trabalho tem como objetivo o diálogo entre duas pesquisas empíricas, no intuito de problematizar o conceito de lugar e afetividade como um modo de conhecer as relações pessoacidade. O primeiro, intitulado "Mover-se na cidade: produção da identidade de lugar em ciclistas" investigou o modo como ciclistas se afetam com o ambiente urbano e se apropriam dele durante seus deslocamentos diários. O segundo, chamado "Experiências afetivas 
urbanas: a relação de cidadãos com sua praça central" procurou compreender a interação habitante - praça pública, e a afetividade implicada em tal relação.

\section{Norteadores teóricos}

Este trabalho é orientado pela perspectiva da psicologia ambiental, que se inscreve no campo do conhecimento interdisciplinar e cujo domínio cruza com disciplinas como a arquitetura, o urbanismo e a geografia. Seus métodos e técnicas de investigação inserem-na área dos estudos pessoa-ambiente, distinguindo-se das referidas disciplinas por lançar o olhar à bidirecionalidade na relação entre as pessoas e o ambiente. Desse modo, tratar da reciprocidade das relações entre as pessoas e seus entornos implica considerar sua complexidade e seus diversos vetores de composição (ambiental, social, econômico, político, afetivo, etc). Entende-se, portanto, que a psicologia ambiental lida com as experiências humanas em sua concretude (Tassara, Rabinovich \& Goubert, 2004), definindo-as em seus aportes ambiental, histórico e psicossocial.

Nas cidades, para além de sua infraestrutura material, a relação pessoa-ambiente se dá de maneira concreta, estabelecida na experiência urbana do morador com os espaços percorridos e utilizados. Estes, por sua vez, não existem isoladamente, senão a partir do sentido atribuído a ele por um grupo social. Uma vez que a psicologia ambiental se volta às questões de ordem prática, a intervenção na esfera ambiental se embasa na vivência das pessoas no urbano, expressa pelas subjetividades ali engendradas, gestadas no espaço e no tempo (Tassara \& Rabinovich, 2001).

A ideia da co-construção pessoa-cidade, bem como a interface existente entre produção da subjetividade e da cidade, reforçam a premissa da psicologia ambiental a respeito da transacionalidade (Rivlin, 2003; Valera, 1996). Nesse sentido, compreende-se que as relações pessoa-ambiente são definidas de maneira mútua e dinâmica, considerando que estabilidade e transformação são coexistentes e que as transações humano-ambientais constituem uma via de mão dupla (Valera, 1996).

Para entender a relação entre as pessoas e os lugares, é necessário atentar para as especificidades conceituais de "espaço" e "lugar" empregados nos estudos pessoa-ambiente. O espaço denota amplidão, movimento e liberdade e remete ao aspecto físico, à concretude, às dimensões e delimitações de uma área: o espaço pode conter objetos inanimados, seres vivos, e todo tipo de matéria; e pode ser identificado a partir de uma referência espacial. Portanto, o espaço pode ser medido entre dois pontos, dois objetos, criando distâncias e demarcações. Já a constituição de lugar pode demandar 
pouco ou mais tempo, e, ao contrário da noção de espaço que denota movimento, o lugar é definido como pausa, porque implica relação e vínculo (Cavalcante \& Nobrega, 2011; Tuan, 1983).

Do ponto de vista da geografia humana, lugar e espaço estão intimamente relacionados e não podem ser definidos separadamente. Para Tuan (1983), o espaço é dado pela capacidade de se mover: é possível tomar consciência dele pelo simples esticar dos braços e das pernas. O lugar, por sua vez, é a parada, a pausa no movimento, o que permite que este se torne um centro de valoração para aquele que o experimenta (Tuan, 1983).

Por se tratar da experiência humana no espaço, a dimensão do lugar remete aos significados e ao universo simbólico das pessoas em seus entornos. A definição de espaço e lugar aludida por Tuan (1983) pode sugerir uma polarização entre movimento e parada, trânsito e pausa, mobilidade e imobilidade. Discussão também proposta por Sennet (2000), o vínculo que as pessoas estabelecem com os lugares pode, por vezes, ser entendido pela imagem do enraizamento. Frequentemente referida como um modo de captar a identidade grupal em uma localidade específica, a noção de enraizamento confunde a imobilidade com o senso de pertencimento a um lugar particular no mundo, o que reforça a noção de identidade como algo estagnado e minimiza o movimento inerente à vida nas cidades.

No entanto, como espaço e lugar são conceitos que não podem ser definidos separadamente, é necessário inserir o movimento e a parada no próprio lugar. Santos (2014) entende que os lugares são feitos de fixos e fluxos, e o movimento é aquilo de vivo que os reveste (Hissa \& Corgosinho, 2006). Assim, o lugar aglutina significados, histórias individuais e coletivas e subsidia a construção de identidades, ideia que vai de encontro àquilo que possa sugerir encerramento, finalidade ou que dê o caráter de permanência.

Entretanto, a possibilidade de acessar o lugar se dá em ato, em sua experiência. O lugar é o terreno dos encontros, do cotidiano e das histórias, não sendo, portanto, o movimento o que retira seu estatuto de existência. Para Hissa \& Corgosinho (2006, p. 12): "Mesmo movimentando-se, a maioria dos homens encontra-se em um lugar. Ali, no lugar, a existência dos homens adquire o sentido da vida". Logo, o lugar representa a tensão existente entre movimento e parada, e seus ritmos e fluxos não retiram sua condição de lugar.

Desse modo, se o lugar é aquilo que permanece mesmo em movimento, é possível pensá-lo como uma construção constante que se dá na relação entre o ambiente e a sociedade. Ele é tecido por uma rede de significados vinculados ao espaço que se amalgama à história civilizatória e individual e é produtora de identidades (Carlos, 2007).

Definir o conceito de lugar por esse prisma exige pensá-lo concomitantemente em termos objetivos e subjetivos. Da mesma 
maneira como é admitida a existência de um substrato material e concreto referente à espacialidade do lugar, essa superfície espacial é recoberta por uma camada de vida, o lugar só existe na e pela experiência das pessoas ao longo do tempo: é o lugar pensado, apropriado, vivido (Carlos, 2007), e a vida só é possível em ato. Assim, por ser uma construção social e histórica, o lugar é um disparador dos processos de produção de subjetividades, identidades e de apropriação do espaço, que têm a afetividade como aspecto constitutivo.

Assim, se o lugar e o espaço se produzem nas práticas cotidianas, podem ser inseridos no registro da política ${ }^{1}$. De maneira análoga, se consideradas como experiências subjetivas, estão inscritos no registro do sensível. Compreendê-la nesses termos pode auxiliar no entendimento de como os espaços de uso diário podem se tornar significativos mesmo estando em movimento, enriquecendo os significados da relação pessoa-cidade.

Bomfim (2010) sinaliza que a afetividade é um modo de conhecer a cidade, pautado na racionalidade ético-afetiva (Sawaia, 1995) como potência de criação de espaços onde ressoem os interesses e necessidades da coletividade. Essa postura possibilita a invenção de zonas de movimento e a recriação permanente da existência coletiva no território da cidade (Sawaia, 1995).

No mesmo sentido, Bomfim (2010) pontua que a categoria de afetividade na psicologia ambiental e social sintetiza o encontro dos indivíduos com a cidade. Logo, a interação com o espaço não se dá simplesmente pela ocupação corporal, mas principalmente pela significação e apropriação do espaço, o que lhe garante caráter de lugar, este eminentemente relacional. A formação de laços com o ambiente físico não se dá descolada de uma compreensão éticopolítica dos afetos, o que abre caminho para a apreensão dos modos como as pessoas se engajam com os lugares de sua história, relacionam-se com os outros e agem sobre sua realidade socioespacial.

Desse modo, a afetividade é um ponto de transmutação do social e do psicológico, pois ao mesmo tempo em que é um vetor que potencializa a capacidade de ação (dimensão política), favorece 0 encontro dos indivíduos com sua capacidade de manutenção do ser, o que remete a si mesmo e à coletividade (dimensão ética). Por isso, salienta Bomfim (2010), a afetividade é uma dimensão mediadora na ação-transformação.

Trata-se de um conceito filiado à tradição da filosofia de Espinosa, que entende 0 afeto como "[...] as afeç̧ões do corpo pelas quais a potência de agir desse corpo é aumentada ou diminuída, favorecida ou entravada, assim como as ideias dessas afecções" (Espinosa, $1677 / 1992$, p. 267). Para o filósofo, os afetos sobrevêm nas relações estabelecidas com outros corpos e com o mundo. Esses encontros 
provocam modificações nas capacidades dos corpos para a ação e impelem o pensamento a novas direções, que podem variar positiva ou negativamente.

Logo, há afecções boas, que aumentam a potência de agir, e constituem a alegria; e afecções más, que diminuem a potência de agir e compõem a tristeza. Portanto, para Espinosa, a alegria e a tristeza dão as nuanças afetivas das experiências humanas (Espinosa, 1677/1992; Sawaia, 2000). Ademais, não há inferência de causalidade na relação mente e corpo, como por exemplo, sugerir que as emoções "começam" no corpo e afetam a mente - ambos estão em igualdade de potência, que se manifesta tanto psíquica como fisicamente.

A compreensão das afeç̧ões auxilia na discussão acerca da afetividade. Nesses termos, entende-se que a afetividade é o tom emocional da existência humana e é vivenciada como sentimentos e emoções. Estas como fenômeno afetivo intenso e breve, centrado em um objeto e que interrompe o fluxo normal dos acontecimentos; aquelas como reações moderadas de prazer e desprazer em relação a dado objeto (Sawaia, 2000). As emoções são provocadas por objetos ou situações específicas e são momentâneos, como por exemplo, o medo e a cólera. Por sua vez, os sentimentos são as emoções matizadas pela cultura, que são submetidas aos processos cognitivos, e podem ser duradouros (Poncela, 2011).

Na compreensão das dinâmicas urbanas, pode-se tomar a afetividade como aquilo que medeia a relação entre as pessoas, sendo que na posição do outro se situam outras pessoas ou a própria cidade. Bomfim (2010) expõe que a cidade não é somente um palco de interações, mas uma parte com a qual se forma uma totalidade em que eu e mundo, espaço construído e subjetividade formam uma "unidade pulsante".

Extrapolando para o cotidiano na cidade, a afetividade é mais que o vínculo do habitante com seu lugar, diz respeito a "[...] todos os sentimentos e emoções que, em seu conjunto, demandam disposições afirmativas ou negativas, positivas ou negativas, que configuram uma afetividade em relação ao espaço construído e vivido" (Bomfim, 2010, p. 55). Os mesmo sentimentos ou emoções podem ser percebidos como bons ou ruins: serão bons quando deles emergem relações de igualdade que aumentam a potência de ação; e ruins quando explicitam relações de humilhação e sofrimento, que diminuem a capacidade de agir (Sawaia, 2000).

Enfocar a afetividade por esse prisma permite considerar a cidade como lugar de encontros, da produção de relações, onde o outro se impõe como diferença. As pessoas não se afetam sozinhas, e é por isso que a afetividade é um termômetro para a ética, política e cidadania (Bomfim, 2010). Ela indica as formas de engajamento das 
pessoas na cidade e sinaliza para a abertura dos corpos ao regime do sensível.

\section{As pesquisas: metodologia, resultados e discussão}

As duas pesquisas apresentadas, embora tenham sido realizadas em diferentes contextos, figuraram como disparadores da discussão acerca do lugar como produção humana. Ambos os estudos embasaram-se do conceito de afetividade como um modo de compreender as inter-relações das pessoas com a cidade, e, a partir desses entendimentos em comum, é que foram selecionados os fragmentos das narrativas que subsidiaram a interlocução entre as duas investigações.

Importante destacar que as pesquisas tiveram objetivos e estratégias de produção dos dados diferentes. Entretanto, ambas conduziram à problematização da compreensão de lugar, na medida em que procuraram promover a tensão na relação lugar-pausa e espaçomovimento. A seguir são expostos de forma sucinta e separadamente, o método de cada pesquisa e os resultados selecionados que, por sua vez, subsidiam a discussão. Por fim, são tecidas as considerações finais que congregam apontamentos e ponderações despertados por tais estudos.

\subsection{Estudo 1: Ciclistas e a cidade}

Pedalar pode ser uma oportunidade de vivenciar a cidade em outra velocidade, experimentar outros ângulos de seu território, percorrer seus caminhos no tempo suportado pelo próprio corpo. Para além da objetividade dos deslocamentos utilitários e dos trajetos cujas distâncias são empecilhos para alcançar o destino final, a bicicleta como meio de transporte pode ser um modo de produzir vínculos entre pessoa e cidade. Nestes, entende-se que a afetividade é a dimensão que medeia a relação das pessoas com os espaços transitados e dispara a capacidade de agir e transformar a realidade (Bomfim, 2010).

Este estudo analisou as relações entre ciclistas ${ }^{2}$ e o cenário urbano de Florianópolis - SC, com interesse em descrever o modo como as pessoas se identificam com os lugares por onde transitam. Tal processo de identificação com o entorno pressupõe uma maneira de agir, conhecer e se afetar com o ambiente, de modo que a resposta à pergunta "quem sou eu" passa pela significação e apropriação do ambiente.

Os dados foram produzidos em duas etapas complementares, uma centrada no ambiente e outra na pessoa. A primeira se embasou na caracterização das estruturas disponíveis para ciclistas nos entornos 
da Universidade Federal de Santa Catarina (UFSC). Na segunda, ciclistas que pedalam como meio de transporte foram entrevistados seguindo um roteiro semiestruturado de entrevista visando identificar os motivos para a escolha da bicicleta, das barreiras e facilitadores para seu uso e dos componentes afetivos da relação ciclista-cidade. Para este estudo foram utilizados os dados oriundos da segunda etapa de coleta.

Foram entrevistados 18 universitários de ambos os sexos, selecionados por conveniência e seguindo a técnica da bola de neve ${ }^{3}$. Incluíram-se aqueles que: 1) utilizassem a bicicleta como meio de locomoção ao menos uma vez na semana; fossem vinculados à UFSC; 3) tivessem se deslocado de bicicleta até a Universidade ao menos uma vez no semestre em que foram realizadas as entrevistas. Foram incluídos participantes até que o conteúdo das entrevistas apresentasse a saturação ou redundância de informações. Os participantes possuíam idade entre 21 e 37 anos (média de 25 anos) e utilizavam a bicicleta como meio de transporte entre um e cinco anos. Em relação aos deslocamentos, relataram a realização de uma a quatro viagens diárias que duram em média de 20 a 30 minutos.

Sob a forma de sentimentos e emoções, a afetividade foi caracterizada como aquilo que potencializa a capacidade de os ciclistas agirem e transformarem seu entorno, bem como o que despotencializa tal disposição. Em relação àquilo que move os ciclistas ao encontro dos lugares, ressaltam-se as marcas corporais que o ciclismo imprime como a exposição ao ambiente, ao sol e ao ar puro. Além disso, emoção, adrenalina e euforia, palavras evocadas como definidoras do encontro do ciclista com a cidade, reforçam a potência do ambiente em afetar o corpo. Nesse sentido, uma das participantes evocou a imagem da bicicleta como uma extensão do corpo, ou seja, um aparato que além de ser um meio de transporte e de experimentar a cidade, amplia a superfície de contato do ciclista com o lugar por onde transita.

Por outro lado, diminuem a capacidade de ação-transformação das condições de circulação os sentimentos e emoções despotencializadores. Nesses termos, seja pela falta de estrutura para circular na cidade ou pela falta de respeito de outros integrantes do trânsito com o ciclista, os participantes relataram a sensação de insegurança e desamparo provocada pela exposição a algumas situações cotidianas. Por vezes, pedalar é estar entregue ao devir, ou seja, saber que existe o risco de vida se houver algum descuido por parte do outro ou do próprio ciclista. Do alheamento às condições do trânsito advém a angústia, o receio e o medo.

Esses sentimentos são a ligação do ciclista com a cidade e auxiliam na construção da uma imagem da cidade em um todo, integrando seus aspectos positivos e negativos. Também é um modo de situar a pessoa em seu entorno, de localizá-la, de modo a produzir uma 
totalidade com a cidade. Tais sentimentos sugerem a implicação do ciclista com a cidade, possibilitando escapar à compreensão da cidade como um território passagem, um pano de fundo desligado das pessoas que nela transitam e de entendê-la como núcleo produtor de sentidos e lugares, estes compartilhados, vivenciados e intersubjetivos.

Essa implicação afetiva se refere às afecções ciclista-cidade, que retratam o modo como o ciclista é afetado pelas situações do trânsito e pela paisagem urbana de Florianópolis. O que caracteriza esse aspecto são as intensidades e velocidades, algo que por vezes não pode ser nomeado, mas produz uma marca, afeta.

Nesse sentido, a bicicleta acaba sendo, ela própria, um veículo afetivo que conduz o ciclista ao encontro da cidade e de seus lugares. Não se trata, portanto, de uma descrição de cenários e das belezas naturais de Florianópolis, mas sim da composição com esse plano, em que o ciclista não é um elemento destacado do fundo, mas é antes de tudo parte dele. Ao retratar sua experiência, uma das participantes relatou que de pedalar não se resume a passar pelos lugares. De bicicleta "[...] tu passa como observador, tu tá participando daquele local, tu tá fazendo parte. Eu sinto isso, porque a bike é totalmente aberta, então [...] tu tá em contato [...] e acaba descobrindo, vivendo as cenas que você passa durante a pedalada" (sexo feminino, 22 anos).

Se a afetividade é o indicador da implicação das pessoas com a cidade (Bomfim, 2010), o relato da participante sugere que experimentar a cidade pedalando possibilita aliar-se à paisagem. Vivenciá-la, descobrir a cidade, ver e sentir suas irregularidades e inconsistências: retratos da experiência urbana incorporada. Como sugerem Hissa e Nogueira (2013), ver a cidade é vivê-la, experimentá-la, é uma aliança indissolúvel entre corpo e cidade que, quando mediada pela bicicleta, torna-se ainda mais explícita. Nesse caso, a propulsão humana dita o ritmo do deslocamento e as barreiras do trajeto são transpostas pelo esforço físico de quem pedala. Entre suor e gratificação, adrenalina e descobertas, corpo e cidade se tecem reciprocamente.

Entende-se que os ciclistas observam e vivem a cidade sob uma perspectiva diferente, experimentando diariamente os prazeres e dificuldades inerentes a essa atividade. Diante de um cenário que não foi projetado para a circulação com bicicletas, a aliança entre o desenho da cidade e a cultura do automóvel localiza o ciclista em uma posição espacial específica.

No contexto em que a rua é do carro, a calçada é do pedestre e o "corredor" entre as pistas pertencem aos motociclistas, os ciclistas são convocados a adotarem uma postura que os colocam em risco, como costurar o trânsito, subir na calçada, desviar das pessoas e dos carros, circular entre os carros. Por mais que os ciclistas se considerem parte do trânsito e admitam que as vias devam ser 
compartilhadas por diversos modais, prevalece o cenário em que todo mundo tem pressa, cada um quer ser o primeiro, quer tirar uma vantagem e ninguém entende ninguém, e que é necessário um pouco de fé de que nada acontecerá.

Diante dessas condições o ciclista é convocado a se posicionar no espaço e a ocupá-lo. Por exemplo, impor-se no trânsito foi uma das estratégias utilizadas pelos participantes para se fazerem visíveis e, de certa forma, reivindicar sua posição. Não ficar próximo ao meio fio e ocupar a faixa refletem a postura adotada para lidar com as disputas do trânsito. Assim, os ciclistas relataram que em locais com ruas estreitas é necessário pedalar no centro da pista, acompanhando o fluxo dos carros e, de certa forma, impedir que a ultrapassagem dos outros veículos os coloquem em risco.

Portanto, o modo como é concebida a mobilidade urbana postula uma hierarquia entre os modais que, diferente do que é proposto em termos legais, prevalece um modo hegemônico de circulação. Se a legislação define a prioridade dos meios não motorizados em detrimento dos motorizados e os públicos sobre os privados, as experiências dos ciclistas na cidade de Florianópolis demonstraram algo que se distancia dessa situação ideal. Portanto, do ponto de vista histórico a circulação motorizada é entendida como "adequado" de se locomover nas cidades, uma vez que estas produziram aparatos robustos para o fluxo de automóveis. Nesse contexto, o ciclismo é entendido como algo marginal, como definiu um dos participantes: "O ciclismo é sempre estar figurativamente e literalmente à beira da estrada, na margem... Ciclista via de regra está na margem" (sexo masculino, 23 anos).

Distante da posição de vítima do trânsito e frente à falta de condições ideais de circulação, os participantes descreveram algumas estratégias de resistência a essas ausências, tomando justamente a potência de sua "errância" como motor para transformar essa realidade. Justamente por sua condição marginal, sempre à beira (da pista, das políticas, dos meios de transporte), e muitas vezes por não ter um lugar específico para transitar, os ciclistas se utilizam desse lugar a eles atribuído para circularem da maneira que quiserem. Pedalar acaba sendo um deslize, uma costura nas vias da cidade, desafiando as práticas instituídas nesse cenário.

Apesar das condições nem sempre ideais para a circulação, o uso da bicicleta como meio de transporte foi citado pelos participantes como um modo de produzir encontros. Nesse sentido, um argumento recorrente foi que o pedalar é quase sempre compartilhado e apesar de parecer uma atividade individual, o ciclista está disposto a ter um contato os outros e com a natureza. É, portanto, um meio de encontrar e estar com outras pessoas e de produzir proximidades ao sair para pedalar com pessoas da mesma tribo, visitar amigos, ir à praia, tomar um café com uma pessoa querida. 
Apesar de esses encontros parecerem finalidades do uso da bicicleta, o que predomina no discurso é a tonalidade afetiva dessa prática, ou seja, a potência do pedalar como um fator de ligação entre as pessoas. Desse modo, estar exposto ao ambiente, ao contato visual e corporal com o outro pode ser algo que deixe o ciclista aberto aos acasos do caminho, à possibilidade de reduzir a velocidade, parar, encontrar ou simplesmente perceber que a pessoa ao lado passa por dificuldades semelhantes às suas.

Sobre a bicicleta, o contato e os encontros se dão em movimento, particularidade que os caracterizam como efêmeros e incertos. No entanto, eles possuem densidade o bastante para se organizarem como subcategoria dos conteúdos analisados, uma vez que são acontecimentos significativos que produzem memória e afetam. Desse modo, entende-se que a bicicleta é um instrumento que deflagra a potência do lugar (no caso, a cidade) em produzir encontros e afetar.

Como sugeriu um participante, pedalar envolve a disposição para estar em contato. Mesmo parecendo algo casual, os encontros com o outro e com o ambiente são possíveis sob certas condições. Do ponto de vista individual, faz-se referência à dimensão ética da afetividade, - que permite tratar da cidade como terreno privilegiado de alterização (Sawaia, 1995). Da perspectiva macroscópica, os encontros são agenciados pelas formas e desenhos urbanos que configuram a cidade como um sistema aberto (Sennet, 2006) ou organizada para pessoas (Gehl, 2010), arranjos que pressupõem a vida nas cidades.

Nos contextos urbanos, a afetividade indica a possibilidade de as pessoas se apropriarem dos espaços e se identificarem com eles. Nesse sentido, a criação de vínculos afetivos com os entornos implica em ética e cidadania (Bomfim, 2010), ou seja, na criação de modos mais solidários de uso do espaço e de condutas que visem à conservação do ambiente e à circulação compartilhada. Sob a ótica do ciclista, trata-se da possibilidade de produzir lugares, "ilhas" de intensidades afetivas que resistem àquilo que na cidade é somente piche e concreto. Desse modo, o transporte "lento" pode ser uma maneira de estar em contato, de se permitir afetar pelo entorno, de vivenciar o lugar e estar aberto à relação com os outros e com o ambiente, com todas as ambivalências que isso possa sugerir.

\subsection{Estudo 2: A praça e o habitante da cidade}

Em meio às cenas urbanas de agitação, ruídos e pressa, alguns lugares despontam como ilhas que permitem às pessoas reconectarem-se perceptual, cognitiva e afetivamente ao seu entorno. Perceber a praça pública como uma destas "ilhas" foi o que motivou a investigação, que se ancorou na afetividade como 
categoria de análise para compreender e descrever a relação dos habitantes com sua praça central, no município de Campos Novos SC. A pesquisa contou com duas etapas de coleta: uma etapa observacional, que empregou o mapeamento comportamental para caracterizar a semana típica de uso da praça, e uma etapa de entrevistas semiestruturadas. Neste trabalho, serão discutidos apenas os dados oriundos das falas dos entrevistados.

A escolha dos participantes foi do tipo intencional não-probabilístico, de acordo com os seguintes critérios de inclusão: a) residir no município há pelo menos seis meses da data da entrevista; b) o participante considerar-se um frequentador da praça, mesmo que eventual; e c) ser maior de 18 anos. Foram realizadas 14 entrevistas (nove mulheres), cujas idades variaram entre 18 anos e 85 anos. $O$ tempo de residência na cidade variou entre seis meses e 57 anos. A inclusão de participantes ocorreu até que o conteúdo das entrevistas apresentasse a saturação ou redundância de informações. As pessoas foram abordadas na praça em diferentes horários e dias da semana, e em todas as áreas da praça (e.g. parque infantil, academia ao ar livre, área de bancos e pergolados), na expectativa de captar distintos olhares e percepções dos frequentadores do local. As entrevistas foram transcritas e passaram por análise temática de conteúdo. Para o presente trabalho, foram selecionados apenas os fragmentos de falas que serviram como dispositivo para discutir os conceitos de lugar e afetividade.

A praça estudada passou por processo de reconstrução em 2012, e o comportamento de reapropriação da praça pela comunidade local foi fator preponderante para sua seleção como contexto de pesquisa. $\mathrm{Na}$ presente proposta de discussão o foco recai sobre os aspectos relacionados à afetividade manifestada na e pela cidade, e que se constitui como categoria mediadora entre a pessoa e a praça pública. Afetividade que congrega o concreto e o subjetivo, a mente e o corpo, a razão e a emoção (Bomfim, 2010) e serve como ponto de partida para as histórias que escolhemos aqui contar.

Cássia é professora e mora à quase dois quilômetros da praça. Pelo menos uma vez por semana estaciona seu carro na região central da cidade: precisa ir ao banco, ao correio, à papelaria - e a Praça está incluída em seu roteiro de andanças pelo centro. Ela adora as flores, e descreve seu trajeto predileto: "(...) da fonte para a casa da cultura (...) além do colorido, é a alameda que forma entre a fonte e o fundo lá, da casa da cultura". Cássia cruza a praça "por vontade", poderia usar outros caminhos, mas passa por ali porque percebe que sente "bem estar" e acha que as flores são as responsáveis por isso. A estética parece ser um dos principais elementos que afetam e alteram as potências dos corpos que circulam naquela praça - mas não é o único. 
Assume-se que os afetos advêm nas relações estabelecidas com um "outro", que pode ser a cidade, o banco da praça, a flor, a pessoa desconhecida que passa e deseja um bom dia - tais sentimentos e emoções modificam as capacidades dos corpos para a ação e impelem os pensamentos a novas direções. Nesta perspectiva, ao serem convidados a discorrer sobre a praça, os entrevistados o fizeram por meio das cognições, emoções e sentimentos que compõem a afetividade: é o "sentir" como ferramenta para "conhecer" a praça. Durante as entrevistas, algumas pessoas remeteram-se aos aspectos físicos da praça - suas percepções e motivos relacionaram-se à concretude do ambiente físico e sua interação com ele. De forma distinta, alguns entrevistados, quando perguntados sobre o seu "estar na praça", fizeram referência a sentimentos e emoções despertados pelo lugar, sem preocupar-se com a descrição dos elementos físicos. Como em uma paleta de cores, as falas revelaram múltiplas tonalidades dos afetos do corpo e da alma.

Quem mora ou trabalha no entorno da Praça já deve estar acostumado com a presença do aposentado Nelson na academia ao ar livre, todos os dias, pontualmente às cinco horas da tarde. Para ele, que já completou 60 anos de idade, a ida a praça não é apenas lazer: virou prescrição médica. Após um episódio depressivo, Nelson descobriu que ir à praça diariamente trouxe "alívio" físico e emocional, e, depois que contou ao médico sobre o tal "alivio", a praça ingressou no receituário mensal.

Em sua fala simples, Nelson traduz a concepção espinosana de que as afecções podem aumentar ou diminuir a potência de agir do corpo e das ideias. Para ele, o estar na praça resulta em aumento de sua potência e vontade de viver. Ele elogia o paisagismo da praça, e lista atributos que transcendem os aspectos concretos do ambiente. Fala da possibilidade de convivência com mais pessoas, do "aconchego" que sente, e completa: "[...] sinto alívio no corpo [...] me sinto mais feliz, mais animado". Sem nunca ter ouvido falar em Espinosa, o aposentado nos brinda com a Alegria: "[...] sinto aquela alegria, você respira ar puro, você ouve ainda o canto dos passarinhos que têm bastante aqui no final da tarde". Ao tomar a afetividade como mediadora das relações, podemos pensar a praça pública como lugar de encontro: encontro com a cidade e encontro com as outras pessoas. E se for palco para os bons encontros, a praça carrega a marca da Alegria, de onde emergem relações de igualdade.

$\mathrm{Na}$ fala dos entrevistados, a permanência na praça remete a descanso, relaxamento, tranquilidade, aconchego, bem estar e alívio - estas menções associam-se, em geral, a aspectos da jardinagem e da beleza. Sentimentos de paz, harmonia e aconchego também são apontados como fatores que estimulam o retorno ao local. 0 sentimento de admiração foi associado ao aspecto estético da praça, 
cuja beleza foi mencionada por todos os entrevistados. Para aqueles que percebem a praça como "distração", "diversão" e "lazer", os sentimentos são de bem estar e alegria - tais menções estão relacionadas, em geral, aos encontros que os entrevistados têm com outras pessoas, e podem assumir múltiplas formas: conversar com um amigo, olhar os filhos brincar, observar os transeuntes.

Os bons encontros permitem a conexão do habitante com a cidade enquanto lugar, onde são tecidas biografias. Mais do que espaço para descanso ou para travessia, a praça pública, assim como a rua e a calçada, podem assumir relevância histórica na vida dos indivíduos, pois serve como representação concreta de eventos da vida, e permite às pessoas compararem presente e passado através das lembranças a eles associados. Nasce daí a dimensão ética da afetividade (Sawaia, 2000), quando há envolvimento e identificação com o lugar, que remete a si e à coletividade. São histórias produzidas e partilhadas na realidade socioespacial dando forma aos entalhes da vida urbana.

João declara: "Venho aqui para pensar na vida". Enquanto João "pensa", em outro canto da Praça, Maria aquieta: "Venho aqui para esvaziar a cabeça, esquecer os problemas". Naquela Praça é comum encontrar pessoas sozinhas, caminhando com passadas lentas, paradas em pé ou sentadas em banco. A possibilidade de permanecer no local para pensar, meditar, relaxar e esvaziar os pensamentos é referida como motivação para ir à praça, e permite aos entrevistados reconectarem-se à cidade e a si mesmos. Sentimentos de estima pela cidade (Bomfim, 2010) brotam dos momentos de meditação, enquanto observam o chafariz, a flor, o idoso que passa.

A praça é convite para pausa e para movimento, para sentar na grama e para ser atalho no centro da cidade. Por conta disso figura como bom exemplo quando se pensa o lugar como produção humana, cujos ritmos e fluxos não retiram sua condição de existência enquanto lugar (Hissa \& Corgosinho, 2006), já que não é a ausência do movimento que o define: o lugar desvela-se nas inter-relações de pessoas e o espaço concreto, e é um processo de construção sócio histórico.

Ora, se é um processo de co-construção, e se o desafio é compreender as inter-relações entre pessoas e ambiente dentro da premissa da transacionalidade sugerida pela Psicologia Ambiental, não se pode considerar o habitante e o espaço público em um jogo de figura e fundo. Se pessoa e ambiente constituem-se como um todo e são figura - a proposta é tomar a vida urbana como fundo, para pensar as relações. A experiência com este ambiente físico que não é apenas contexto - mas produto e produtor de histórias - nos instiga, como propõe Lefebvre (2001), a "considerar a utopia experimentalmente" para se pensar espaços favoráveis à felicidade. 
E qual seria este espaço favorável à felicidade? Na praça estudada, a multifuncionalidade e o aspecto inclusivo do espaço foram percebidos como aspectos que impactam positivamente a percepção que os cidadãos têm do local. A Praça comporta a coexistência de reuniões, atividades físicas, concertos musicais, teatro, piquenique, feiras, serviços religiosos, manifestações de ONGs, e permite sua apropriação por um grande número de habitantes da cidade, que manifestam interesses distintos. Fica a pergunta: a configuração física pode contribuir para a pluralidade, ou a simples condição de ser "público" a garante?

A Praça erige-se como zona de tensão: sua ocupação é plural, e múltiplos discursos e práticas ali convivem. Há quem relate as discussões da comunidade no jornal local, do que seria o uso daquele espaço: skate ou caminhada? Idosos ou crianças? Calma ou pressa? Silêncio ou ruído? Não há consenso, todos continuam lá, congregando os dissensos e contradições da cidade, e garantindo o "direito à vida urbana" (Lefebvre, 2001) que se transforma e se renova - e só na cidade encontra sua realização prático-sensível.

\section{Considerações finais}

Este trabalho objetivou a articulação entre duas pesquisas que trataram de modos diferentes de experimentar a cidade: um que remete à parada e outro ao movimento. Embora distintas, ambas as experiências se tangenciam pelo viés afetivo, ou seja, no modo como a cidade e as pessoas se afetam mutuamente e se desdobram em modos particulares de produção de subjetividades. Reconhecem-se as limitações da presente discussão, na medida em que articular investigações empíricas em contextos diversos é um desafio. Não se pretende esgotar o assunto, pelo contrário, almeja-se, com esses apontamentos iniciais, dar continuidade à reflexão acerca da afetividade como mediadora da relação das pessoas com o ambiente urbano.

Dentre as aproximações possíveis, destaca-se a reflexão sobre o lugar dentro de uma perspectiva que não cristaliza a praça como lugar-pausa e a rua como espaço-movimento. Se o lugar é estabelecido pelas e nas biografias que se constroem no espaço vivido, pode-se pensar que este não implica necessariamente em pausa ou enraizamento, mas se refere antes aos modos como as pessoas se afetam e conectam-se aos espaços experienciados. Assim, tanto a circulação quanto a permanência nos espaços da cidade comportam experiências produtoras de lugares significativos, estes compartilhados coletivamente.

A produção de sentidos e significados se torna possível pela mediação afetiva e pela implicação corporal das pessoas nos lugares. No caso 
dos estudos relatados, estas se dispõem às aberturas e encontros com o outro e com o ambiente, decorrência da implicação éticoafetiva com o entorno. Estar implicado com o entorno indica, portanto, a possibilidade de escapar à compreensão da cidade como um território de passagem, um pano de fundo desligado das pessoas que nela circulam e de entendê-la como núcleo produtor de sentidos e lugares, estes vividos e compartilhados.

Seja pedalando pelas ruas, caminhando na praça ou sentado em um banco à sombra de uma árvore - ao circular desta forma pelos espaços os habitantes sinalizam certa oposição à lógica da velocidade. Eles acenam para a ideia de que nas cidades há algo que resiste, que deseja os bons encontros, e que manifesta outras formas de ocupação e uso dos lugares. Tal ocupação sinaliza a abertura dos corpos a uma experiência prático-sensível e formas outras de implicação com os espaços. Diante disso, a afetividade aponta para a transcendência do que é da ordem concreta e medeia a relação entre as pessoas e as paisagens urbanas, já que os sentimentos e emoções que emergem na relação com os lugares orientam a maneira como os indivíduos habitam, circulam e sentem a cidade.

A afetividade mostrou-se como uma alternativa possível na compreensão dos lugares na cidade, pois medeia a potência de as pessoas agirem e transformarem os espaços por onde circulam ou permanecem. Na discussão de ambas as pesquisas, propõe-se imprimir outra dinâmica (que não a do automóvel) às cidades. Estimular outros modos de circular e/ou permanecer nesses espaços gera a possibilidade dos bons encontros. Velocidades, sensações e afetos dão o tom à experiência urbana e reverberam todos no corpo, produzindo sentidos diversos na relação pessoa-ambiente.

O modo como os ciclistas e os frequentadores da praça se apropriam dos espaços indicam uma demanda de inscrição simbólica no espaço e a necessidade do posicionamento corporal para garanti-lo. Nesse sentido, a afetividade despertada pelos entornos desdobra-se em modos mais solidários de uso do espaço e de condutas que visem tanto ao compartilhamento da cidade quanto o cuidado com os lugares.

\section{Referências}

Bomfim, Z. A. C. (2010). Cidade e afetividade: estima e construção dos mapas afetivos de Barcelona e São Paulo. Fortaleza: Edições UFC.

Carlos, A. F. A. (2007). O lugar no/do mundo. São Paulo, FFLCH.

Cavalcante, S. \& Nóbrega, L. M. A. (2011) Espaço e Lugar. In: Cavalcante, S. \& Elali, G. A. (orgs.) Temas Básicos em Psicologia Ambiental. Petrópolis: Vozes. 182-190. 
Dewes, J. O. (2009). Amostragem em bola de neve e respondentedriven sampling: uma descrição dos métodos. Monografia apresentada para obtenção do grau de Bacharel em Estatística, Universidade Federal do Rio Grande do Sul, Rio Grande do Sul, RS, Brasil.

Espinosa, B. (1677/1992). Ética. Lisboa: Relógio D'Água Editores.

Gehl, J. (2010). Cities for people. London: Island Press.

Hissa, C. E. V. \& Corgosinho, R. R. (2006). Recortes de lugar. Geografias, 2 (1), p. 07-21.

Hissa, C. E. V. \& Mello, A. F. (2008). O lugar e a cidade: conceitos do mundo contemporâneo. In: Hissa, C. E. V. (org.). Saberes ambientais: desafios para o conhecimento disciplinar. Belo Horizonte: Editora UFMG.

Hissa, C. E. V. \& Nogueira, M. L. M. (2013). Cidade-corpo. Revista UFMG, 20(1), p. 54-77.

Lefebvre, H. (2001). O direito à cidade. (5a. Ed). São Paulo: Centauro.

Poncela, A. M. F. (2011). Antropología de las emociones y teoría de los sentimentos. Revista Versión Nueva Época, 26, 1-24.

Rivlin, L. G. (2003). Olhando o passado e o futuro: revendo pressupostos sobre as interações pessoa-ambiente. Estudos de Psicologia, 8(2), p. 215-220.

Santos, M. (2014). A natureza do espaço: técnica e tempo, razão e emoção. 4a ed. São Paulo: Editora da Universidade de São Paulo.

Sawaia, B. B. (1995). O calor do lugar: segregação urbana e identidade. São Paulo em Perspectiva, 9(2), 20-24.

Sawaia, B. B. (2000). Por que investigo afetividade? Texto apresentado para concurso de promoção na carreira para a categoria de professor Titular do Departamento de Sociologia da PUCSP. São Paulo: PUC/SP. Impresso.

Schiller, P. L., Bruun, E. C. \& Kenworthy, J. R. (2010). An introduction to sustainable transportation: policy, planning and implementation. London: Earthscan.

Sennet, R. (2000). Street and office: two sources of identity. W. Hutton \& A. Giddens (Eds.) Global Capitalism. London, Jonathan Cape.

Sennet, R. (2003). Carne e pedra. $3^{a}$ ed. Rio de Janeiro: Record.

Sennet, R. (2006). The open city. Recuperado em 30 de outubro de 2015

de: http://downloads.Isecities.net/0_downloads/Berlin_Richard_Sen nett_2006-The_Open_City.pdf

Tassara, E. T. O. \& Rabinovich, E. P. (2001). A invenção do urbano e o poético: uma cartografia afetiva - estudo sobre o bairro paulistano da Barra Funda. Tassara, E. T. O. (Org.). Panoramas 
interdisciplinares para uma psicologia ambiental do urbano. São Paulo: EDUC.

Tassara, E. T. O., Rabinovich, E. P. \& Goubert, J-P. (2004). O lugar da poética nas relações pessoa-ambiente. O caso da Barra Funda: uma arqueologia de um elo social em vias de desaparecimento. Tassara, E. T. O., Rabinovich, E. P., Guedes, M. C. (Eds.). Psicologia e ambiente. São Paulo: EDUC.

Tuan, Y. (1983). Espaço e lugar: a perspectiva da experiência. São Paulo: DIFEL.

Valera, S. (1996). Psicología Ambiental: bases teóricas y epistemológicas. In: L. Iñiguez \& E. Pol (Eds.). Cognición, representación y apropiación del espacio. Barcelona: Publicacions Universitat de Barcelona, 1-14.

\section{Endereço para correspondência \\ Camila Klein}

Universidade Federal de Santa Catarina - UFSC

Centro de Filosofia e Ciências Humanas, Departamento de Psicologia

Laboratório de Psicologia Ambiental, sala 11B, Trindade, CEP 88040-970, Florianópolis - SC, Brasil

Endereço eletrônico: kleincamila.ck@gmail.com

\section{Ariane Kuhnen}

Universidade Federal de Santa Catarina - UFSC

Centro de Filosofia e Ciências Humanas, Departamento de Psicologia

Laboratório de Psicologia Ambiental, sala 11B, Trindade, CEP 88040-970, Florianópolis - SC, Brasil

Endereço eletrônico: ariane@cfh.ufsc.br

\section{Nikolas Olekszechen}

Universidade de São Paulo - USP

Instituto de Psicologia

Av. Professor Mello Soares, 1721, Cidade Universitária, CEP 05508-030, São Paulo - SP, Brasil

Endereço eletrônico: nikolas.oleks@gmail.com

Recebido em: 03/02/2016

Aceito em: 22/10/2016

\section{Notas}

* Psicóloga, Mestre em Psicologia pelo Programa de Pós Graduação em Psicologia da Universidade Federal de Santa Catarina, Florianópolis - SC. Doutoranda em Psicologia na mesma instituição. Membro do Laboratório de Psicologia Ambiental LAPAM/UFSC.

** Professora titular da Universidade Federal de Santa Catarina, vinculada ao Programa de Pós-Graduação em Psicologia, Florianópolis - SC. Coordenadora do Laboratório de Psicologia Ambiental-LAPAM. Doutora em Ciências Humanas pela Universidade Federal de Santa Catarina. Pós doutorado na Université de Quebec à Montreal e pós doutorado na Universtity of California - Davis.

*** Psicólogo, Mestre em Psicologia pelo Programa de Pós Graduação em Psicologia da Universidade Federal de Santa Catarina, Florianópolis - SC. Doutorando em Psicologia Social pelo Instituto de Psicologia da Universidade de São Paulo (IPUSP). 
1 Ideia defendida por Sawaia (2000), a aliança entre ética e política na compreensão da afetividade não pretende ser um recurso gramatical para aproximar dois conceitos de natureza distintas, mas uma junção ontológica que reforça seu caráter de categoria analítico-valorativa. A dimensão ética da afetividade indica a preocupação com "a virtude como dimensão da verdade", e a dimensão política ressalta "a preocupação com a justiça e o poder".

${ }^{2}$ Entende-se como ciclistas aqueles/aquelas participantes que utilizavam a bicicleta como meio de transporte de um ponto de origem até um campus universitário da cidade de Florianópolis (SC).

3 Os participantes foram escolhidos pela técnica da bola de neve (Dewes, 2013), em que um participante, ao final da entrevista, sugere o nome de outro possível participante que se enquadre nos critérios de inclusão da pesquisa. Com base nisso, o procedimento encaminhou apenas à participação de estudantes, ou seja, não houve respondentes que fossem funcionários ou professores da universidade.

\section{Agradecimentos}

À professora Dra. Andrea Vieira Zanella pelas importantes contribuições e diálogos durante a produção deste artigo.

Às colegas Bettieli B. da Silveira (LAPAM-UFSC) e Ana Beatriz Bastos Alves (Engenharia Sanitária e Ambiental - UFSC) pela colaboração.

A CAPES e à FAPESC, cujas bolsas de estudo viabilizaram ambas as pesquisas. 